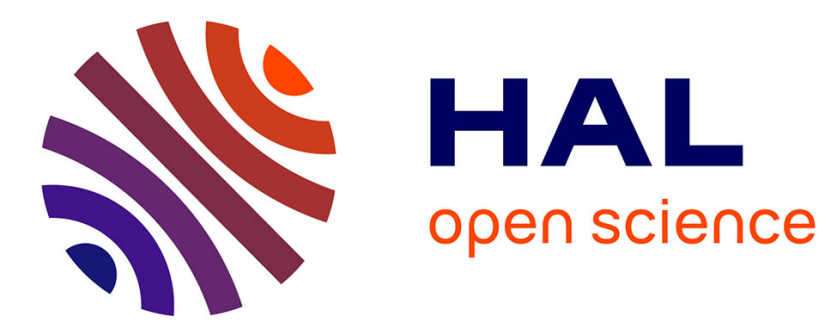

\title{
Economic Hysteresis in Hog Production
}

Jan Hinrichs, Oliver Musshoff, Martin Odening

\section{To cite this version:}

Jan Hinrichs, Oliver Musshoff, Martin Odening. Economic Hysteresis in Hog Production. Applied Economics, 2008, 40 (03), pp.333-340. 10.1080/00036840500447880 . hal-00581959

\section{HAL Id: hal-00581959 \\ https://hal.science/hal-00581959}

Submitted on 1 Apr 2011

HAL is a multi-disciplinary open access archive for the deposit and dissemination of scientific research documents, whether they are published or not. The documents may come from teaching and research institutions in France or abroad, or from public or private research centers.
L'archive ouverte pluridisciplinaire HAL, est destinée au dépôt et à la diffusion de documents scientifiques de niveau recherche, publiés ou non, émanant des établissements d'enseignement et de recherche français ou étrangers, des laboratoires publics ou privés. 


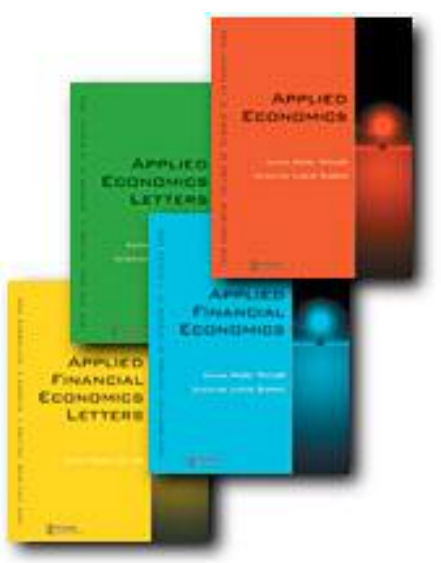

\section{Economic Hysteresis in Hog Production}

\begin{tabular}{|r|l|}
\hline Journal: & Applied Economics \\
\hline Manuscript ID: & APE-05-0328.R1 \\
\hline Journal Selection: & Applied Economics \\
\hline Date Submitted by the \\
Author: & 23-Sep-2005 \\
\hline JEL Code: & $\begin{array}{l}\text { C25 - Discrete Regression and Qualitative Choice Models < , D81 - } \\
\text { Criteria for Decision-Making under Risk and Uncertainty < , Q12 - } \\
\text { Micro Analysis of Farm Firms, Farm Households, and Farm Input } \\
\text { Markets < }\end{array}$ \\
\hline \hline Keywords: & economic hysteresis, risk, real options, hog production \\
\hline
\end{tabular}

powered by ScholarOne

Manuscript Central $^{\text {TH}}$ 


\title{
Economic Hysteresis in Hog Production
}

\begin{abstract}
German hog production only responds in a very limited way to price fluctuations in the pork market. The hog production concentrates on a few regions though it is not bound to special natural conditions such as soil quality. Furthermore, the volume of production does not vary over time. Relatively high market risks, sunk costs, and the flexibility of the decision maker to defer investments characterize decision problems in hog production. Thus the real option approach is chosen to explain the inertia in production capacity. By the use of panel data of specialized hog farms from the German Farm Accountancy Data Network (FADN) an empirical investment model is estimated. Formally, the model has the structure of a generalized ordered probit model. This approach allows to test for economic hysteresis in the adjustment of hog production capacity. The results confirm that uncertainty and flexibility widen the optimal range of inaction.
\end{abstract}

Key words: economic hysteresis, risk, real options, hog production

\section{Introduction}

Intensive livestock farming is characterized by two facts. Firstly, the production hardly seems to respond to the considerable price changes that have occurred during the past decades. Secondly, the spatial allocation of production is rather unequal, though no special natural conditions are required for this business. Such an unequal distribution is not desired by agricultural policy makers. Regions with a high concentration of hog production suffer from environmental problems and farmers face several restrictions when enlarging their capacity. On the other hand, there are also weakly developed regions where investments in livestock farming are appreciated in order to stabilize the rural economy. The question rises of how the observed inertia in hog production can be understood. A promising explanation is offered by the real options theory (see for example Chen and Cheng, 2005 and the literature cited therein). This theory analyses 
investments in a dynamic and stochastic environment. An important finding is that the optimal range of inaction widens when uncertainty and irreversibility are present. Both features exist in the case of hog production due to a volatile hog market and very specific investments in production facilities. In fact, Maung and Foster (2002) calculate option values for the Canadian pork industry and prove the significant effect of risk and flexibility associated with different marketing alternatives. Odening, Musshoff and Balmann (2005) apply the real options approach to investments in hog finishing and demonstrate that investment triggers are much higher than the traditional investment theory (i.e. the net present value) suggests. Moreover, it is shown that it may even be rational to tolerate temporary operative losses before giving up production. However, their results are derived from a normative model and therefore little can be concluded about the actual explanatory power of the new investment theory. In contrast, our paper analyses the investment behaviour of German hog producers empirically. Dynamic adjustments in the pork industry have recently been studied by Pietola and Myers (2000) and Gardebroek (2004) by means of a stochastic adjustment cost model. They find that uncertainty slows down structural adjustments, but their model does not allow to estimate investment and disinvestment hurdles explicitly. The objective of our analysis is twofold. Firstly, we intend to identify determinants that influence capacity adjustments in hog production. An understanding of the adjustment behaviour of hog producers is essential to predict or to control the structural change in this industry. Secondly, from a more theoretical viewpoint we wish to contribute to the empirical validation of real options models. Although more and more applications of this approach are emerging, only few papers try to test its hypotheses empirically (see for example Richards and Green, 2003, Wossink, 2000, Schatzki, 2003, Dong and Saha, 1998). We use a generalized ordered probit model to estimate dynamically optimal thresholds for the expansion and the contraction of production capacities in hog production. This model is applied to panel data from German farms. While standard probit models have already been employed to test for the relevance of the real options theory, to our knowledge this is the first time that a generalized ordered probit model is used in this context.

The paper is organized in five sections. Following this introduction we briefly review the theoretical framework of real options in section II. Section III introduces the econometric 
approach. The model specification and some particular aspects of the data are discussed in section IV. The estimation results and their compatibility with hypotheses derived from the real options are reported in section $\mathrm{V}$, before concluding in the final section.

\section{Theoretical Framework}

Consider an investor who has to decide between immediately investing in a project or waiting and deferring the investment decision. Investing causes sunk costs $I$ and yields an infinite stream of stochastic returns $R$. A standard assumption is that the returns follow a geometric Brownian motion:

$d R=\mu R d t+\sigma_{R} R d z$

$\mu$ and $\sigma_{R}$ are the drift rate and the volatility respectively; $d z$ represents a Wiener-process.

Formally, the decision problem has the structure of an optimal stopping problem and can be solved by dynamic programming. $F(R)$ denotes the value of the investment opportunity. Assuming an infinite time horizon the Bellman equation of the stopping problem becomes:

$r F d t=E(d F)$

$r$ stands for an exogenous interest rate. Carrying out of the common steps to solve the Bellman equation thereby taking into account appropriate boundary conditions yields the following expression for the option value (c.f. Dixit and Pindyck 1994):

$F(R)=A R^{b}$

$A$ is a constant and $b$ is given by

$b=\frac{1}{2}-\frac{\mu}{\sigma_{R}^{2}}+\sqrt{\left(\frac{\mu}{\sigma_{R}^{2}}-\frac{1}{2}\right)^{2}+\frac{2 r}{\sigma_{R}^{2}}}>1$

The continuation region, where the optimal decision is to keep the investment option alive, and the stopping region, where it is optimal to invest immediately, are separated by a threshold $R^{*}$, the so-called investment trigger (trigger return, hurdle rate). This critical value is given by

$R^{*}=\frac{b}{b-1}(r-\mu) I$

The factor $b /(b-1)>1$ is termed the option multiple. Obviously, the optimal trigger return exceeds the classical Marshallian trigger $(r-\mu) I$. The decision rule (5), which is independent 
of the risk attitude of the investor, expresses the famous investment reluctance. It means that an immediate investment is not necessarily optimal, if the present value of investment returns only just covers the investment costs. Comparative static analysis of (5) shows that the investment trigger increases if the sunk costs $I$, the volatility $\sigma_{R}$, and the interest rate $r$ increase and if the drift rate $\mu$ decreases.

The standard real options model has been extended in different directions. For example, Dixit (1989) considers investment and disinvestment decisions simultaneously. A closed form solution for this problem, comparable to (3) and (5), requires restrictive assumptions. However, it can be shown that the optimal capital adjustment strategy satisfies:

$$
\begin{aligned}
& d K>0 \text { if } R(t)>R_{u}^{*}>C+r I \\
& d K=0 \text { if } R_{l}^{*}<R(t)<R_{u}^{*} \\
& d K<0 \text { if } R(t)<R_{l}^{*}<C-r L
\end{aligned}
$$

Herein $K$ denotes the capital stock, $C$ the variable costs of production, $R_{u}^{*}$ the investment trigger and $R_{l}^{*}$ the disinvestment trigger. $L$ is a lump-sum cost, which the firm must incur in case of a disinvestment. If the firm earns a liquidation value, $L$ is negative. Clearly, the condition $I+L>0$ must hold. $C+r I$ and $C-r L$ represent the classical entry and exit triggers respectively. (6) reveals that the sole presence of sunk costs already causes economic hysteresis. Uncertainty and flexibility however, drive a wedge between the classical triggers and as a consequence the range of inaction widens. (6) forms the basis for the econometric model that we describe as follows.

\section{Econometric model}

From the previous discussion it becomes apparent that the investment and disinvestment triggers are crucial to the optimal capital adjustments. Hence we attempt to estimate the optimal decision rule in terms of $R_{u}^{*}$ and $R_{l}^{*}$. According to (6), at any discrete time $t$ the probability of observing a capital reduction, inaction, and a capital expansion respectively, for the $i$-th firm is given by: 


$$
\begin{aligned}
& \text { Disinvestment } \operatorname{Pr}\left(d K_{i t}<0\right) \quad=\operatorname{Pr}\left(R_{i t}-R_{l i t}^{*}+\varepsilon_{i t} \leq 0\right) \\
& =\operatorname{Pr}\left(\varepsilon_{i t} \leq R_{\text {lit }}^{*}-R_{i t}\right) \\
& =\Phi_{\varepsilon}\left(R_{l i t}^{*}-R_{i t}\right) \\
& \text { Inaction } \quad \operatorname{Pr}\left(d K_{i t}=0\right) \quad=\operatorname{Pr}\left(R_{i t}-R_{\text {lit }}^{*}<\varepsilon_{i t}<R_{\text {uit }}^{*}-R_{i t}\right) \\
& =\Phi_{\varepsilon}\left(R_{u i t}^{*}-R_{i t}\right)-\Phi_{\varepsilon}\left(R_{l i t}^{*}-R_{i t}\right) \\
& \text { Investment } \quad \operatorname{Pr}\left(d K_{i t}>0\right) \quad=\operatorname{Pr}\left(R_{i t}-R_{\text {uit }}^{*}+\varepsilon_{i t} \geq 0\right) \\
& =\operatorname{Pr}\left(\varepsilon_{i t} \geq R_{u i t}^{*}-R_{i t}\right) \\
& =\Phi_{\varepsilon}\left(R_{\text {uit }}^{*}-R_{i t}\right)
\end{aligned}
$$

$\varepsilon_{i t}$ are random shocks with $E\left(\varepsilon_{i t}\right)=0$ and distribution $\Phi_{\varepsilon} \cdot \varepsilon_{i t}$ captures stochastic effects that interfere in the relation between the investment returns and the threshold values $R_{\text {uit }}^{*}$ and $R_{\text {lit }}^{*}$. (7) has the structure of an ordered probit model. This relation becomes clear if we consider $R_{i t}+\varepsilon_{i t}$ as the latent variable of the probit model and realize that the investment trigger is always larger than the disinvestment trigger. Note that the thresholds $R_{\text {uit }}^{*}$ and $R_{\text {lit }}^{*}$ are not constant but depend on economic variables $X_{i t}$ which may be firm specific and/or time varying. In general, the relation between the triggers and the vector of control variables can be described as:

$R_{u i t}^{*}=f_{u}\left(X_{i t}, \beta_{u}\right)$ and

$R_{l i t}^{*}=f_{l}\left(X_{i t}, \beta_{l}\right)$

$\beta_{u}$ and $\beta_{l}$ are parameter vectors that have to be estimated. Pudney and Shields (2000) introduced the term 'generalized ordered probit model' for this class of models. Our model is a special case showing a trivial structure of the latent variable. Under the assumption that the errors $\varepsilon_{i t}$ are independent and normally distributed with standard deviation $\sigma_{\varepsilon}$, the $\log$ likelihood function of the model is

$$
\begin{aligned}
L^{*}=\log L\left(\beta_{u}, \beta_{l} \mid d K_{i t}, X_{i t}, R_{i t}\right) & =\sum_{d K_{i t}<0} \log \left(\Phi_{\varepsilon}\left(\left(R_{l i t}^{*}-R_{i t}\right) / \sigma_{\varepsilon}\right)\right) \\
& +\sum_{d K_{i t}=0} \log \left(\Phi_{\varepsilon}\left(\left(R_{u i t}^{*}-R_{i t}\right) / \sigma_{\varepsilon}\right)-\Phi_{\varepsilon}\left(\left(R_{l i t}^{*}-R_{i t}\right) / \sigma_{\varepsilon}\right)\right) \\
& +\sum_{d K_{i t}>0} \log \left(1-\Phi_{\varepsilon}\left(\left(R_{u i t}^{*}-R_{i t}\right) / \sigma_{\varepsilon}\right)\right)
\end{aligned}
$$

It is well known that the marginal effects of the regressors on the probabilities in an ordered probit model, $\operatorname{Pr}\left(d K_{i t}<=>0\right)$, are not equal to the parameters $\beta_{u}$ and $\beta_{l}$. Moreover, it is not 
possible to determine the impact of the regressors on the probabilities simply by inspecting the sign of the coefficients, at least not for the inaction case $d K_{i t}=0$ (cf. Greene, 2000, p. 877). This complicates the interpretation of the results in general. A peculiarity of our model is that a change of the independent variables $X_{i t}$ does not shift the distribution of the latent variable but the thresholds $R_{\text {uit }}^{*}$ and $R_{\text {lit }}^{*}$. Due to this fact, the effect of a regressor on the probability of being inactive is unambiguous, if the corresponding coefficients have opposite signs (increase (decrease) of $R_{u i t}^{*}$ and decrease (increase) of $R_{l i t}^{*}$ ). If, in contrast, the coefficients are both positive or both negative it is not clear whether the probability of observing inaction increases or decreases.

\section{Data and Model Specification}

The analysis utilizes panel data of specialized hog producers from the German Farm Accountancy Data Network (FADN) ${ }^{1}$. The sample consists of an unbalanced panel of 211 farms over a period from 1996 to 2002. To define the dependent variable of the ordered probit model we measure changes of the production capacity for each farm and period. An extension of the production capacity indicates that the expected returns of an investment exceed the investment threshold. Conversely, a reduction of the production capacity indicates that the expected returns fall below the exit trigger. If no adjustment of the production capacity is observed it implies that the expected returns of hog production lie in the inaction region, i.e. between the investment and the disinvestment trigger. To be specific, a farm is assigned to the investment regime, if the average stock of hogs increases more than 20 percent from one year to the other and the total capital stock of the farm increases at the same time. A decline of the average stock of hogs of more than 20 percent together with a non-increase of the total capital (after depreciation) are interpreted as disinvestment while all other cases are considered as inaction. Admittedly, this definition is arbitrary in a way, but additional calculations with alternative rules for the assignment to the three regimes did not change the results significantly.

The functions $f_{u}$ and $f_{l}$ in (8) are approximated by linear functions, i.e. 


$$
\begin{aligned}
& R_{u i t}^{*}=\beta_{u}^{\prime} X_{i t} \text { and } \\
& R_{l i t}^{*}=\beta_{l}^{\prime} X_{i t}
\end{aligned}
$$

In this respect our approach is similar to that of Richards and Green (2000) or Tufano and Moel (2002). The independent variables $X_{i t}$ cover the following areas: investment returns, investment costs and production costs, uncertainty and flexibility. Table 1 summarizes the definitions and some descriptive statistics of the exogenous variables as well as their hypothesized impact on the (dis)investment trigger.

\section{Table 1 about here}

\section{Investment and production costs}

Investment costs $I\left(\equiv x_{1}\right)$ are derived from the position "buildings" and "technical equipment" shown in the balance sheets of the farms. Both the real options theory and the traditional investment theory predict a positive effect of investment costs on the investment trigger. Differences occur with respect to the influence of the investment costs on the disinvestment or contraction trigger. In a static context only the variable costs and the scrap value determine the disinvestment trigger. In a dynamic view adopted by the real options theory, the investment costs also play a role. An active farmer will wait longer before giving up or shrinking production if re-entry or expansion induces sunk costs again. This of course is only true, if a costless temporary suspension of production is impossible.

Since we express the trigger values in terms of revenues of hog production (and not as gross margins), variable production costs $C\left(\equiv x_{2}\right)$ have an influence on these thresholds. Unfortunately, the complete variable production costs are not shown in the financial statements. The costs for farrows, which constitute a major part of the variable costs, are used as a proxy. Nevertheless, it is likely that further cost components not covered by $x_{1}$ and $x_{2}$ influence the (dis)investment decision. For example, costs for planning and building permission arise. They depend on the intensity of livestock production and increase significantly if an administrative 
threshold of 2.0 livestock units per hectare is exceeded. Moreover, intensive hog producers incur higher costs for the acquirement of manure quota. Hence the variable 'livestock units per hectare', $x_{3}$, is included in the estimation model.

Another variable that may impact on the costs and thereby affect the (dis)investment trigger is the financial structure of the farm. Standard real options models implicitly assume perfect capital markets, i.e. money can be borrowed or invested at a risk free rate without restrictions. However, Lagerqvist and Olson (2001) prove empirically that a higher financial leverage reduces the investment activities in US farms. The explanation they offer is that debt financing causes higher adjustment costs. Following this line of argumentation we include the debt share of the farms, $x_{4}$, into the set of explanatory variables.

\section{Investment returns and uncertainty}

The investment returns are derived from the revenues from hog sales that are displayed in the income statements. Total revenues are translated into revenues per place assuming a turnover rate of 2.6. However, these figures are silent about the way of how farmers build their expectations of future returns and their volatility. The standard real option model presumes a geometric Brownian motion. Applying a Dickey-Fuller test to average annual revenues from hog production in Germany provides empirical evidence for this assumption in the present case.

The consideration of risk is of particular importance for the validation of the real options theory. Several authors emphasize the sensitivity of option values and investment triggers with respect to the volatility of the investment returns (e.g. Schatzki, 2003 or Moel and Tufano, 2002), but it is often difficult to control for this variable in econometric models. The use of panel data in the present application offers the opportunity to estimate farm specific volatilities. This is advantageous, because different marketing and risk management strategies leading to differences in the risk exposure of individual producers are taken into account. Table 1 shows that the risk inherent to hog finishing in fact varies considerably between farms. As stated in 
section II, the investment trigger increases with increasing volatility. Moreover, it can be shown that the disinvestment trigger falls when the project returns become more volatile. This means that increasing risk widens the optimal range of inaction.

\section{Flexibility}

The valuation of real options is closely connected to the measurement of flexibility. If no flexibility prevails, the new and the traditional investment theories coincide. The standard real options model in section II considers the option to defer an investment and assumes that this option does not expire. This simplifying assumption allows to derive the closed form solution (3), but it is not a very realistic one. Investment opportunities may vanish in the course of time for different reasons. To illustrate this point, think of tightening environmental regulations that will rule out certain types of intensive animal husbandry in the future. Moreover, the farmer's flexibility to time the investment optimally will diminish with his increasing age, at least in family farms which constitute the majority in our sample. But if we concede that flexibility varies between farms and over time, this aspect should enter the empirical model. There are some attempts to quantify flexibility in the context of real options. For example, Ramezani (2003) measures managerial flexibility by the firms' expenditures for research and development. We prefer a narrower interpretation of flexibility in the sense of it measuring the time until the (dis)investment option expires. Option pricing theory tells us that the change of the option price with respect to the passage of time, i.e. the option theta is usually negative. In other words: the time value of the option decreases in the course of time and the value of the unexercised option converges to the intrinsic value. Quite analogously, the trigger values converge on their classical counterparts. It is tempting to approximate the time period to maturity of the (dis)investment option by the farmer's age, but the loss of flexibility will be interfered by another effect. The older a farmer is, the more likely it is that he does not receive the full returns of the investment. In order to get an unambiguous relation between the age and the investment trigger we suggest using the absolute deviation between 45 and the farmer's age, $x_{8}$. This proposal is motivated by the observation that the investments considered have an average operating life of about 20 years and that farmers usually retire at the age of 65 . 


\section{Fixed effects and random effects}

A prevalent problem related to the analysis of panel data is unobserved heterogeneity in the population. That means individual effects exist for each case (farm), which are not covered by the explanatory variables of the regression model. Ignoring these effects can lead to biased or inefficient parameter estimates. In the present application such effects may arise from differences in the farm manager's education, in the location or the legal status of the farm. Two main approaches are discussed in the literature to cope with this issue, the fixed effects approach and the random effects approach (Arellano, 2003). Fixed effects models assume that differences between individuals are constant over time and can be captured by differences in the constant term of the regression model, i.e. by dummy variables. Due to the fact that our sample includes more than 200 farms, it is practically unfeasible to assign a dummy variable to each unit. A step in that direction is to distinguish between intensive production regions (Lower Saxony and North Rhine-Westfalia, $x_{5 i}=1$ ) and less intensive production regions (all other states, $x_{5 i}=0$ ). This distinction is motivated by possible differences in the production costs. Moreover, according to Porter's (1990) cluster theory a high regional concentration of an industry can lead to cost advantages.

The second approach, the random effects model, views individual specific terms as randomly distributed across the units. This view seems more appropriate to our case, since the farms under consideration are a sample drawn from a larger population. Random individual effects are taken into account by including a second error term in the model. The relevance of individual random effects can be tested by a Lagrange-Multiplier test (Breusch and Pagan, 1980). For our data we obtain an LM test statistic of 2.10 which falls below the critical value on a 95 percent significance level, 3.84. Hence the null hypothesis of no individual effects cannot be rejected. This finding justifies to conduct a pooled regression. 


\section{Results and discussion}

As mentioned above, the empirical residuals of the generalized ordered probit model (7) neither show any significant correlation nor an autocorrelation between farms. Hence the maximum likelihood method will provide asymptotically efficient estimates. The log likelihood function (9) is maximized with respect to $\beta_{u}$ and $\beta_{l}$ using (10). $X_{i t}$ is specified as described in the previous section. Table 2 summarizes the estimation results.

\section{Table 2 around here}

First of all, a pseudo $\mathrm{R}^{2}$ value of 0.71 indicates a good overall fit of the model. Before we turn to the discussion of the partial effects of the explanatory variables we calculate the average investment and disinvestment trigger by multiplying the parameter estimates with the average values of the regressors $X_{i t}$. The corresponding values are 553 and 127 euros respectively per place. That means, an average farmer extends his production capacity whenever the returns in hog finishing exceed 553 euros per place and year. Conversely, the production capacity is reduced, if the returns fall below a threshold of 127 euros per place and year. In order to assess the magnitude of these figures a comparison with the classical Marshallian triggers would be helpful. Since the empirical model does not allow for an endogenous calculation of the classical triggers you have to derive them separately. According to average planning data for Germany, variable costs of hog finishing amount to 260 euros. This value constitutes the classical exit trigger. Apparently the estimated disinvestment trigger only covers 50 percent of the variable costs. The classical investment trigger is approximated as follows: The average investment costs in our sample are 604 euros. An assumed operating life of 20 years, an interest rate of 6 percent and a wage rate of 15 euros per hour lead to fixed costs of 78 euros per place and year. Adding fixed and variable costs gives a classical total expense of 338 euros, which is considerably less than the estimated value of 553 euros. Hence our results confirm the hypothesis that the endogenously calculated investment triggers (disinvestment triggers) in hog production exceed (fall below) their classical counterparts. In average the range of inaction is more than five times higher compared with a situation without uncertainty and flexibility. 
Many of the parameter estimates support the hypotheses of the real options theory. As expected, investment costs $\left(x_{1}\right)$ increase the investment trigger. The corresponding parameter estimate $\beta_{u 1}=0.03$ can be interpreted as a (risk free) interest rate. The impact on the disinvestment trigger is negligible. This result is not implausible, since in practice a reduction of the production capacity does not always go along with a disinvestment, but can also be the result of a temporary suspension of the production. The costs for such an interruption (e.g. transaction costs, contract penalties) are not necessarily related to the investment costs. The coefficients of the variable costs $\left(x_{2}\right)$ have the correct sign and are significant, at least for the investment case.

Hog producers with a high stock rate and farms located in intensive production regions do not have higher investment triggers. This indicates that the aforementioned potential advantages and disadvantages of an intensive and spatially concentrated production balance out. It is remarkable that the disinvestment trigger is lower in the two regions with intensive hog production.

The hypothesis of leveraged farms exhibiting higher investment reluctance is rejected by the data: the coefficient $\beta_{u 4}$ is not significant. Apparently additional debt capital can be acquired without increasing marginal costs - a result that seems to contradict previous research on the impact of the capital structure on the investment behaviour in agriculture (e.g. Barry et al., 2000). It should be noted, however, that the financial leverage of the investing farms is rather low on average (0.23). Moreover, a detailed analysis of the relation between capital structure and the investment behaviour requires considering the investment volume and the availability of internal financial funds. These factors were not taken into account in the present analysis.

Conclusions from the relevance of the new investment theory are usually based on the investigation of the sign and the significance of the estimated parameters of the risk variable. In fact, the coefficients have the sign that is predicted by the real options theory $\left(\beta_{u 7}=3.01\right.$, $\left.\beta_{l 7}=-6.19\right)$. The average volatility of the returns from hog production amounts to 26 percent. 
Multiplication with the two coefficients results in an average increase (decrease) of the investment trigger (disinvestment trigger) of 79 euros (163 euros) compared to a situation with certain returns. Hence the investment risk is a key factor for the understanding of the inertia in this sector. Unfortunately, a negative relationship between the investment activity and uncertainty cannot be uniquely attributed to the existence of real options. Alternatively, such a finding could simply be explained by the risk aversion of decision makers. While this problem has been described in the literature it has not been solved yet. As a way out we propose to look at the interaction of uncertainty and flexibility. In the context of the new investment theory, both uncertainty and flexibility are required to increase the range of inaction. Simple risk aversion on the other hand, works independently of flexibility. This distinction permits to separate the two causes of investment reluctance. For an implementation of this idea we divide the sample into two subsets, the one showing high and the other low flexibility. Again, flexibility is defined in terms of the expiration time of the (dis)investment option, which is approximated by the farmer's age. At the same time the variable $x_{8}$ is removed from the model. A separate estimation of the model with the two data sets reveals that the impact of risk is more pronounced if farms have higher flexibility: the coefficients of the risk variable $x_{7}$ are $\beta_{u 7}=3.98$ and $\beta_{l 7}=-6,96$ for the more flexible group, whereas the corresponding values of the less flexible group are 0.31 and -0.74 . That means, the observed inertia of the capacity adjustment can be (at least partially) assigned to option-like hysteresis.

\section{Summary and Conclusions}

The understanding of the dynamics of capacity adjustments in agriculture is an important issue, since (dis)investments determine the direction and the velocity of structural changes. Accordingly, many attempts have been made in agricultural economics to explain these decisions, technological, financial as well as sociological models being amongst them ${ }^{2}$. In the present paper a real options framework is used for analyzing capacity adjustments in the hog sector. Real options models allow to disentangle the joint effects of irreversibility and uncertainty concerning (dis)investment decisions. In our view this is an advantage compared to 
alternative approaches, in particular adjustment cost models. We employ a generalized ordered probit model for an empirical validation of the real options approach. It turns out that many implications of the new investment theory are in harmony with the empirical facts reflected in our data. Empirical evidence for real option models frequently is devaluated by the equivocal effect of uncertainty about investment decisions. One might object to the assertion that it is difficult to distinguish between options effects and simple risk aversion. However, an important feature of our model is the separation of both impacts of uncertainty. We provide evidence that real options actually play a role for the optimal timing of the expansion and contraction of production capacities in the German hog industry.

Of course, the existing real options in hog production cannot fully explain the emergence of production clusters. Nevertheless, real options help to understand why structural adjustment processes in hog production take place rather slowly. Our results draw the attention to sunk costs and uncertainty. An important implication of our results is that the observed inertia in capacity adjustments need not to be interpreted as a kind of inefficiency. The farmers' reluctance to invest does not necessarily express ignorance of profit opportunities or market frictions. It rather is compatible with dynamically optimal behaviour. Hence, a slow capacity adjustment per se provides little justification for state intervention. Such measures should for instance be justified by environmental or regional policy targets. If, on the other hand, it is desirable to speed up adjustment processes and structural changes in intensive livestock production for whatever reasons, the considerable inertia which can be attributed to this sector, has to be taken into account. This knowledge is helpful for the design of measures falling into the second pillar of the CAP like for example investment programmes and retirement programmes. 


\section{References}

Arellano, M. (2003) Panel Data Econometrics, Oxford University Press, New York.

Boehlje, M. (1992) Alternative Models of Structural Change in Agriculture and Related Industries, Agribusiness, 8, 219-231.

Breusch, T, Pagan, A. (1980) The LM Test and its Applications to Model Specification in Econometrics, Review of Economic Studies, 47, 239-254.

Chen, Y.-F., Cheng, I-H. (2005): Protection and employment under uncertainty: a real options approach, Applied Economics, 37, 229-238.

Dixit, A.K. (1989) Entry and Exit Decision under Uncertainty, Journal Political Economy, 97, 620-638.

Dixit, A.K., Pindyck, R.S. (1994) Investment under Uncertainty, Princeton University Press, Princeton.

Dong, D., Saha, A. (1998) He came, he saw, (and) he waited: an empirical analysis of inertia in technology adoption, Applied Economics, 30, 893-905.

Gardebroek, C. (2004) Capital adjustments on Dutch pig farms, European Review of Agricultural Economics, 31 (1), 39-59.

Greene, W.H. (2000) Econometric Analysis, $4^{\text {th }}$ ed., Prentice-Hall, London.

Lagerkvist, C.J., Olson, K.D. (2001) Asymmetric information, capital structure and agricultural investment, Paper presented at the annual meeting of the American Agricultural Economics Association, Chicago.

Maung, A., Foster, K. (2002): Capital Investment under Alternative Marketing Scenarios in the Hog Industry: A Real Option Approach, Canadian Journal of Agricultural Economics, 50 (3), 223-235.

Odening, M., Musshoff, O., Balmann, A. (2005) Investment Decisions in Hog Production- An Application of the Real Options Approach, Agricultural Economics, 32, 47-60.

Pietola, K.S., Myers, R.J. (2000) Investment under Uncertainty and Dynamic Adjustment in the Finnish Pork Industry, American Journal of Agricultural Economics, 82 (11), 956-967.

Porter, M. (1990) The competitive Advantage of nations, Free Press, New York. 
Provencher, B. (1997) Structural versus Reduced-Form Estimation of Optimal Stopping Problems, American Journal of Agricultural Economics, 79, 357-368.

Pudney, S., Shields, M. (2000) Gender, Race, Pay and Promotion in the British Nursing Profession: Estimation of a Generalized Ordered Probit Model, Journal of Applied Econometrics, 15, 367-399.

Ramezani, C.A. (2003): Real options, corporate performance, and shareholder value creation, Paper presented at $7^{\text {th }}$ annual International Real Options Conference 2003, Washington DC.

Richards, T.J., Green, G. (2000) Economic Hysteresis in Variety Selection, Journal of Agricultural and Applied Economics, 35, 1-14.

Schatzki, T. (2003) Options, uncertainty and sunk costs: an empirical analysis of land use change, Journal of Environmental Economics and Management, 46, 86-105.

Moel, P., Tufano, A. (2002) When are real options exercised? An empirical study of mine closings, The Review of Financial Studies, 15, 1, 35-64.

Wossink, A. (2000) The Failure of Marketable Permit Systems and Uncertainty of Environmental Policy: A Switching Regime Model Applied to the Dutch Phosphate Quota Program, Paper presented at the AAEA annual meeting 2000, Tampa. 
Table 1: Summary of the independent variables

\begin{tabular}{|c|c|c|c|c|c|}
\hline \multirow[t]{2}{*}{ Variable } & \multirow[t]{2}{*}{ Mean } & \multirow{2}{*}{$\begin{array}{r}\text { Standard } \\
\text { deviation }\end{array}$} & \multicolumn{2}{|c|}{ Hypothesized impact on } & \multirow[t]{2}{*}{ Definition } \\
\hline & & & $\begin{array}{l}\text { Investment } \\
\text { trigger }\end{array}$ & $\begin{array}{c}\text { Disinvestment } \\
\text { trigger }\end{array}$ & \\
\hline$R$ & $\begin{array}{c}327.5074 \\
€ \\
\end{array}$ & 65.1633 & - & - & $\begin{array}{c}\text { Fattened hog revenues } \\
\text { p.a. and place }\end{array}$ \\
\hline$x_{1}$ & $\begin{array}{l}515.2717 \\
€\end{array}$ & 643.9740 & $\uparrow$ & $\downarrow$ & Investment costs \\
\hline$x_{2}$ & $\begin{array}{l}147.9929 \\
€\end{array}$ & 31.2609 & $\uparrow$ & $\uparrow$ & Farrow costs p.a. and place \\
\hline$x_{3}$ & $\begin{array}{l}3.9740 \\
\text { LU/ha }\end{array}$ & 2.0288 & $\uparrow$ & $?$ & $\begin{array}{c}\text { Number of livestock units } \\
\text { per ha }\end{array}$ \\
\hline$x_{4}$ & $\begin{array}{c}19.7391 \\
\% \\
\end{array}$ & 22.3674 & $\uparrow$ & $?$ & \begin{tabular}{|c} 
Debt share in percent of total \\
assets
\end{tabular} \\
\hline$x_{5}$ & 8 & renta & $?$ & $?$ & $\begin{array}{c}\text { Dummy variable accounting } \\
\text { for regional differences }\end{array}$ \\
\hline$x_{6}$ & $\begin{array}{c}1.1760 \\
\%\end{array}$ & 4.7096 & $\uparrow$ & $\downarrow$ & Drift rate of hog revenues \\
\hline$x_{7}$ & $\begin{array}{c}26.2583 \\
\%\end{array}$ & 6.3470 & $\uparrow$ & $\downarrow$ & Volatility of hog revenues \\
\hline$x_{8}$ & $\begin{array}{c}7.9201 \\
\text { years }\end{array}$ & 5.5996 & $\uparrow$ & $\uparrow / \downarrow$ & $\begin{array}{c}\text { Absolute deviation of } \\
\text { farmers' age from } 45 \text { years }\end{array}$ \\
\hline \multicolumn{3}{|c|}{$\uparrow=$ Trigger increases } & \multicolumn{2}{|c|}{$\downarrow=$ Trigger decreases } & $?=$ Effect unclear \\
\hline
\end{tabular}

Total number of observations $=839$

Number of observations with investment: 64

Number of observations with inaction: 748

Number of observations with disinvestment: 27 
Table 2: $\quad$ Maximum Likelihood estimation results

\begin{tabular}{|c|c|c|c|c|}
\hline \multirow{2}{*}{ Variable } & \multicolumn{2}{|c|}{ Investment } & \multicolumn{2}{|c|}{ Disinvestment } \\
\hline & Parameter & Estimate $^{1}$ & Parameter & Estimate \\
\hline$x_{1}$ & $\beta_{u 1}$ & $\begin{array}{c}0.0302 * * \\
(2.5385)\end{array}$ & $\beta_{l 1}$ & $\begin{array}{c}0.0000 \\
(0.0000)\end{array}$ \\
\hline$x_{2}$ & $\beta_{u 2}$ & $\begin{array}{l}1.1774 * * \\
(17.6445)\end{array}$ & $\beta_{l 2}$ & $\begin{array}{c}0.0000 \\
(0.0006)\end{array}$ \\
\hline$x_{3}$ & $\beta_{u 3}$ & $\begin{array}{c}0.0061 \\
(0.0029)\end{array}$ & $\beta_{l 3}$ & $\begin{array}{c}-7.4532 * * \\
(-3.2083)\end{array}$ \\
\hline$x_{4}$ & $\beta_{u 4}$ & $\begin{array}{c}0.0001 \\
(0.0003)\end{array}$ & $\beta_{l 4}$ & $\begin{array}{c}-0.8863 * * \\
(-2.4280)\end{array}$ \\
\hline$x_{5}$ & $\beta_{u 5}$ & $\begin{array}{c}0.0084 \\
(0.0006)\end{array}$ & $\beta_{l 5}$ & $\begin{array}{c}-22.5902 * \\
(-1.6969)\end{array}$ \\
\hline$x_{6}$ & $\beta_{u 6}$ & $\begin{array}{c}0.0141 \\
(0.0001)\end{array}$ & $\beta_{l 6}$ & $\begin{array}{c}-0.0163 \\
(-0.0002)\end{array}$ \\
\hline$x_{7}$ & $\beta_{u 7}$ & $\begin{array}{c}3.0092 * * \\
(8.5568)\end{array}$ & $\beta_{l 7}$ & $\begin{array}{l}-6.1887 * * \\
(-18.4062)\end{array}$ \\
\hline$x_{8}$ & $\beta_{u 8}$ & $\begin{array}{c}0.9482 * * \\
(2.9167)\end{array}$ & $\beta_{l 8}$ & $\begin{array}{r}-0.0004 \\
(-0.0005) \\
\end{array}$ \\
\hline & $\beta_{0}$ & $\begin{array}{c}275.9767 * * \\
(36.5207)\end{array}$ & $\beta_{0}$ & $\begin{array}{c}275.9767 * * \\
(36.5207)\end{array}$ \\
\hline
\end{tabular}

${ }_{t} t$-ratios are in parentheses;

** indicates significance on a $95 \%$ confidence level

* indicates significance on a $90 \%$ confidence level $\mathrm{R}^{2}=0.7149$ 


\section{Endnotes}

${ }^{1}$ We are grateful to the Federal Agricultural Research Centre (FAL Braunschweig), Germany for making the data available.

${ }^{2}$ Boehlje (1992) provides an overview of these models. 